\title{
The Impact of Dental Implants on Maxillofacial Patient's Quality of Life
}

\author{
Jorge Gonzalez
}

Center for Maxillofacial Prosthodontics, Baylor College of Dentistry, 3302 Gaston Ave, Dallas, TX 75246, USA

\begin{abstract}
Avulsive injuries and ablative surgery for both aggressive benign and malignant disease, even when wellreconstructed, leave anatomy that provides no effective means of stabilizing prosthesis. For such patients, implantstabilized or, preferably, implant-supported restorations have become the ultimate goal. Defects of the entire craniofacial complex, including esthetic and functional problems, can now be addressed much more predictable and completely than ever before.
\end{abstract}

Keywords: Surgical reconstruction, prosthetic reconstruction, distorted anatomy, radiation therapy, implant anchorage, osteoblastic activity.

\section{INTRODUCTION}

"Avulsive injuries and ablative surgery for both aggressive benign and malignant disease, even when wellreconstructed, leave anatomy that provides no effective means of stabilizing a prosthesis" [1]. Surgical consequences are not negligible; depending on tumor location and size, significant substance loss can occur in the maxilla, in the mandible, or on the oral floor. Such defects interfere with major oral functions such as mastication, deglutition, and speech, and lead to facial deformities that can hinder the patient's return to normal social life [2].

Currently for most cancers and other oral lesions, the common treatment is surgical excision and some radiotherapy [3] (Fig. 1).

Therapeutic radiation causes a number of physiologic changes that may adversely affect prosthetic reconstruction. Xerostomia is one of the most common changes associated with therapeutic radiation. In xerostomic patients, the salivary film that is beneficial for denture comfort and adequate denture retention is eliminated or greatly reduced [4]. Decreased salivary flow may be associated with an increase in the rate of dental caries. Although caries in the xerostomic patient are not a direct result from radiation to the teeth, it appears to be a multifactorial problem associated with loss of the buffering capacity and lubrication from the saliva, decreased oral hygiene because of tissue discomfort, and other less obvious factors [5]. A return to near normal caries rate is possible only with meticulous oral hygiene, routine use of topical fluoride, and replenishment of lost mineralized structure with re-mineralizing solutions [6] (Fig. 2). However, it must be emphasized that the demographic picture of the oral cancer patient does not provide optimism for this long-term, extremely diligent approach to oral hygiene. Too often, despite the efforts of the dental team, dental caries continues to be a significant risk to the patient's dentition [5].

\footnotetext{
*Address correspondence to this author at the Center for Maxillofacial Prosthodontics, Baylor College of Dentistry, 3302 Gaston Ave, Dallas, TX 75246, USA; Tel: 214-828-8990;

E-mail: jgonzalez@bcd.tamhsc.edu
}

In recent years, maxillofacial reconstruction has evolved and improved considerably. Substantial loss in the mandible, with or without interruption of bone continuity, can be compensated by sophisticated techniques using pedicle or microanastomosed flaps (e.g., free micro-anastomosed fibula transfer) [7-9]. Symmetry of the lower facial area can usually be preserved, and functional problems can be minimized. Despite surgical reconstruction, some problems remain for dental prosthetic reconstruction, since the support area that stabilizes a conventional prosthesis is reduced [10-11]. In patients with associated maxillary defects, two types of prostheses should be considered: conventional removable and implant supported.

\section{REMOVABLE PROSTHESES}

The prognosis for removable prostheses depends on the quality and quantity of the remaining anatomical structures, the ability of these structures to tolerate increased physiologic demands from dental prostheses, and the capacity of the patient to accept the artificial prostheses [5].

Conventionally, clasps or attachments have been used to provide retention for dental prostheses, as well as engaging undercuts in the surrounding tissues and residual dentition to support extensive cantilevers. Such lever system eventually precede a cyclic redistribution of adverse load patterns and subsequent deterioration of the mechanical retentive system, creating a need for supplemental support [12].

In addition, it is difficult to maintain maxillary and mandibular prostheses in satisfactory condition over the long term because of a variety of factors, including recurrence or metastasis of the primary tumor, ulceration, or myelitis. Irradiated patients who wear a non-stable tissue-supported prostheses are at risk for mucosal ulceration, bone exposure, and, ultimately, osteoradionecrosis [1].

\section{OBTURATOR PROSTHESES}

An obturator prosthesis is a removable intraoral device that is frequently used in cases of maxillary resection resulting in an oral, nasal, sinus cavity communication, decreased palatal support, and partial loss of the maxillary vestibule. Surgical compensation in such maxillary defects is 


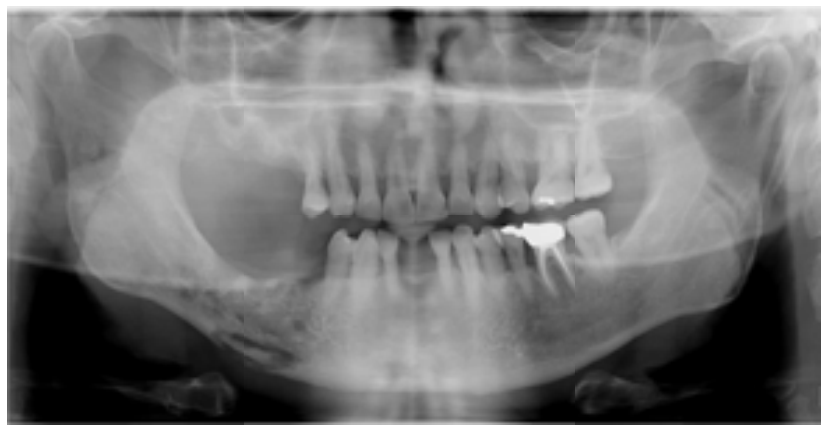

$\mathrm{a}$

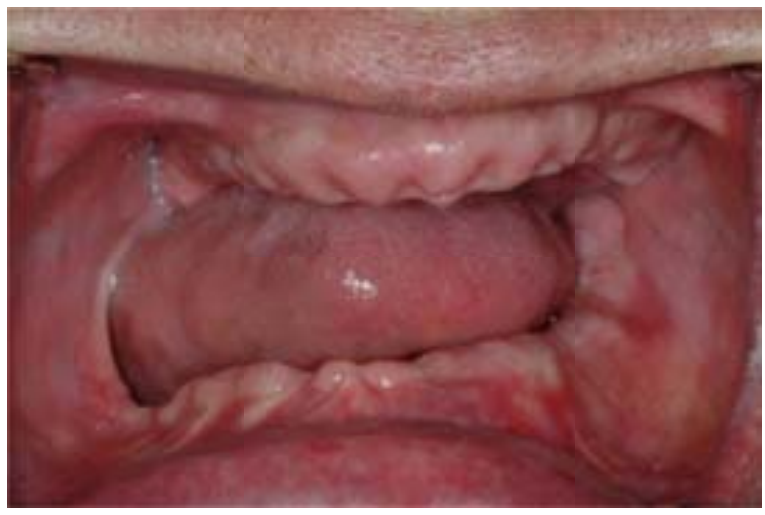

C

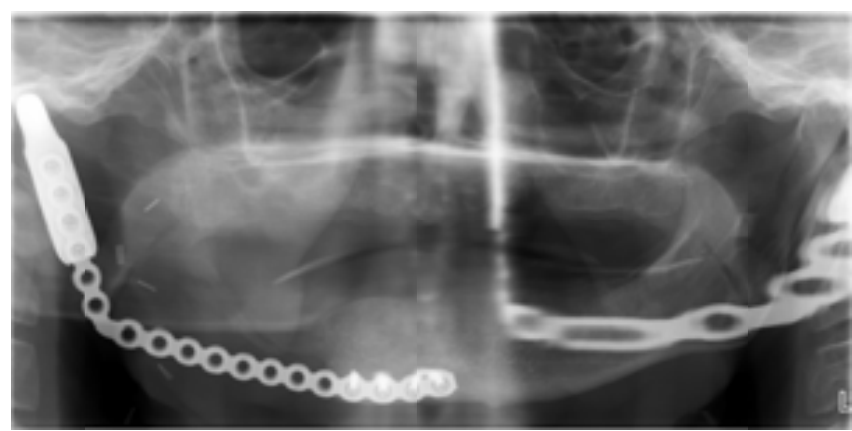

b

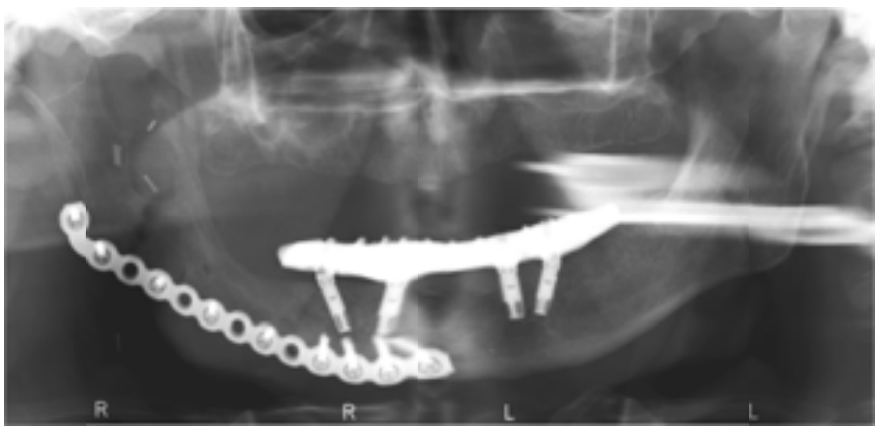

d

Fig. (1). Surgical and prosthetic reconstruction. a; patient diagnosed with Osteomylitis, b; resection of lesion, condyle, ramus and part of the mandibular body was removed, reconstructive plates and prosthetic condyle insertion, c; reconstruction of osseo-defect with hip grafting, note disparity between arches, $\mathbf{d}$; consolidation of graft and implant fixed detachable prosthesis in placed.

not commonly achievable and construction of obturator prostheses can be a difficult due to poor retention and persistent instability of the device (Fig. 3). An advantage of the obturator prosthesis is that it is noninvasive in nature, and allows for clinical re-evaluation and possible early detection of pathology relapse [7].

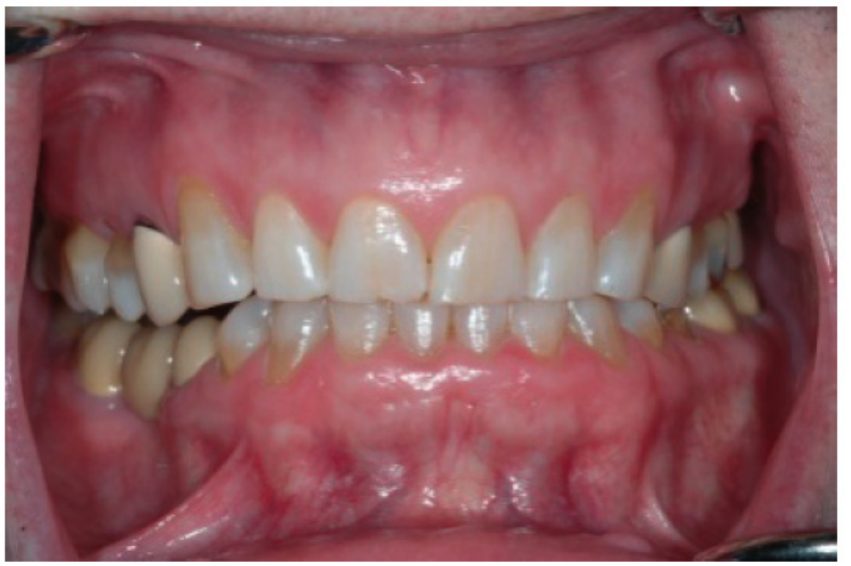

Fig. (2). Xerostomic patient. Xerostomia induced by radiation therapy. Normal caries rate is possible only with meticulous oral hygiene and routine use of topical fluoride.

\section{OSSEOINTEGRATED ENDOSSEUS IMPLANTS}

Osseointegrated endosseus implants have become a reliable treatment modality and provide primary support, retention, and stability for dental prostheses [13,14]. An appropriate number of well-positioned implants can be used to eliminate the intimate soft tissue contact required in conventional removable prosthodontic treatment. The use of dental implants appears to be advantageous for fixation of various types of oral and maxillofacial prostheses in patients with malignant oral tumors $[15,16]$.

The indication for implant placement in irradiated patients remains controversial and some authors still consider implant placement in irradiated patients to be contraindicated [17] because the healing capacity of the bone has been diminished and the process of osseointegration may be impaired. It is also known that irradiation of established osseointegrated titanium implants results in backscatter. Therefore, the tissues $1 \mathrm{~mm}$ surrounding the implants receive approximately $15 \%$ higher dose of radiation than the other tissues in the field [18]. This occurrence increases the risk of soft tissue dehiscence and osteoradionecrosis, and may lead to implant failure $[19,20]$. Granstrom, et al., recommended that all abutments and superstructures should be removed prior to radiation and that soft tissues should be closed over the implant fixtures. Radiation therapy could be administered 


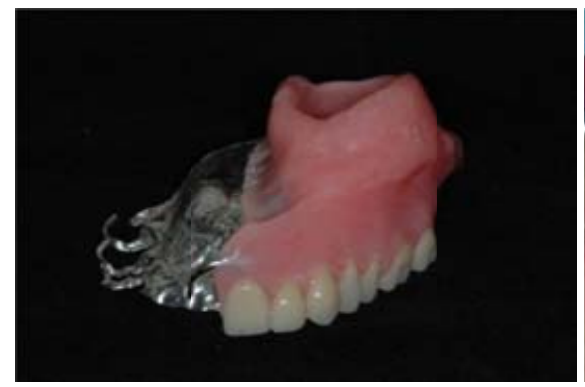

a

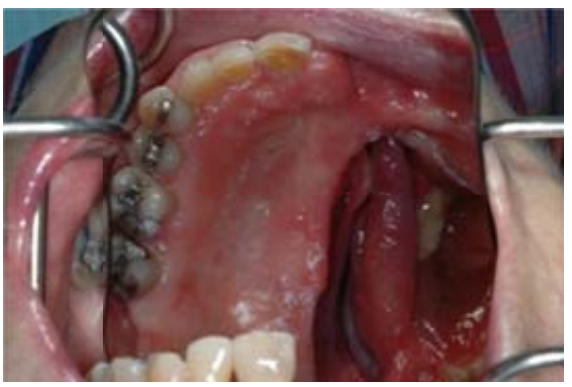

b

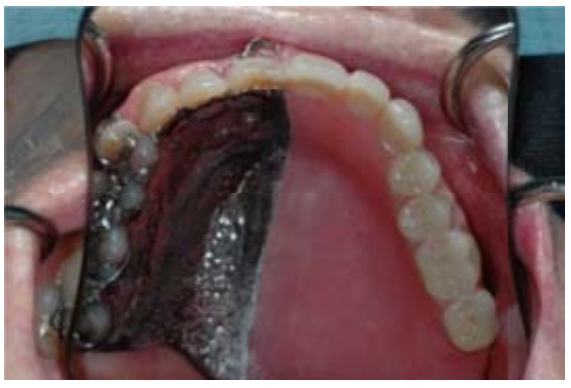

C

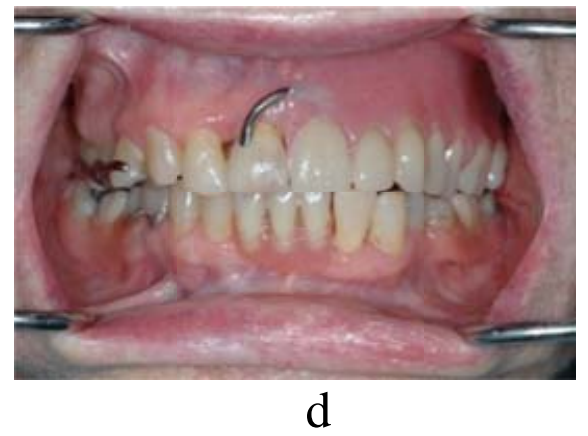

Fig. (3). Obturator prosthesis a; Obturator prosthesis with hollowed bulb design, b; maxillary defect, Left quadrant, c and d; obturator in placed.

once soft tissue was completely healed. Following completion of radiation, the abutments and superstructure could be reattached and the prosthesis remade or modified [21].

Marx and Granstrom have suggested that hyperbaric oxygen therapy (HBO) should precede implant surgery in order to decrease an anticipated loss of implants. HBO is believed to increase osteogenesis and the healing of soft tissues, as well as the neovascularization process in cases of chronic hypoxia [22].

\section{IMPLANT RETAINED PROSTHESES}

Implant retained prosthesis can vary from fixed detachable (Fig. 4) to removable overdenture (Fig. 5). Overdentures can be designed as a combination of implant retained and tissue supported restoration.
Zitzmann and Marinello have indicated the necessary inclusion criteria for planning implant treatment, and indications for fixed or removable prosthesis [23]. Moreover, it has been reported in the literature that when treating maxillary edentulous patients using implants, those with removable prostheses generally tended to show higher failure rates than those with fixed restorations. This can be explained due to the lack of cross-arch stabilization on overdenture prostheses [24].

\section{ADVANCES IN TECHNOLOGY \\ Bone Graft Augmentation}

Predictability of free bone grafts augmentation from iliac crest or temporal bone sources have been significantly improved due to a new generation of titanium bone screws and mini-plates. Such devices can rigidly fix grafts to the recipient sites and avoid micromovement.

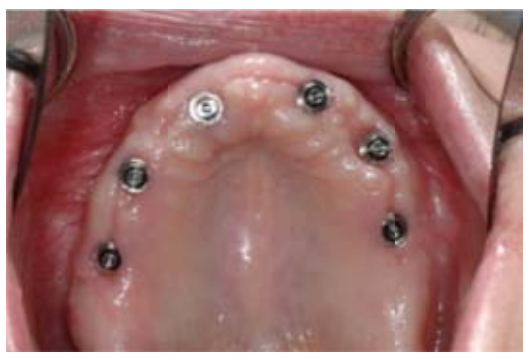

$\mathrm{a}$

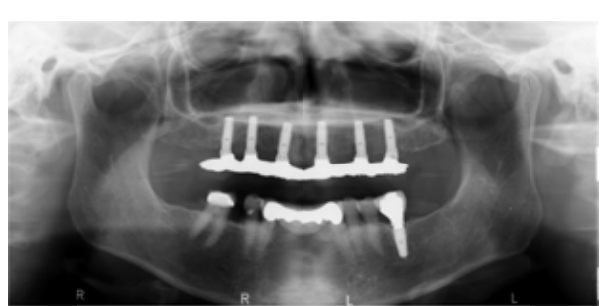

b

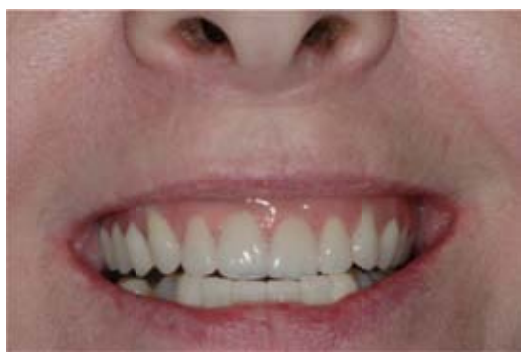

C

Fig. (4). Fixed detachable prosthesis. a; well distribution and anterior-posterior spread of the implants, b; metal framework attached to implants, c; fixed detachable prosthesis in placed. 
Present reconstructive techniques include pedicle or free microvascular flaps, which transfer both bone and soft tissue to the compromised oral area with an immediate source of blood supply to the graft.

\section{Recombinant Human Bone Morphogenetic Proteins 2}

Bone morphogenetic proteins (BMPs) are a group of osteoinductive, sequentially arranged amino acids and polypeptides that are capable of stimulating cells to become osteoblastic and form bone [25]. Recent human studies of maxillary sinus floor grafting have demonstrated the ability of rhBMP-2 delivered on an absorbable collagen sponge (ACS), to induce new bone formation in the sinus without adverse sequelae [26] (Fig. 6). In March, 2007, the Food and Drug Administration approved the use of rhBMP-2 "as an alternative to autogenous bone graft for sinus augmentations, and for localized alveolar ridge defects associated with extraction sockets" [27]. The data from the initial studies demonstrated that the rhBMP-2/ACS placed in maxillary sinuses produced new bone that was capable of supporting dental implants. Tissue engineered osteoinductive grafts may someday eliminate the need for harvesting corticococancellous grafts [1].

\section{Zygomaticus Implants}

Innovative utilization of endosseous implants as remote implant anchorage [12] has remarkably broaden the dental practitioner's capabilities by increasing prosthesis stability and preserving tissue (Fig. 7). Patients with challenging maxillary defects may benefit from the remote bone anchorage of the zygomatic implant, developed by Branemårk [28]. Zygomatic implants require intraoral access to the zygomatic buttress area between the premolar and first molar, through a trans-sinus approach ending at the junction of the zygomatic arch and the lateral orbital rim. The zygomatic implant ultimately engages bone for osseointegration in both the zygoma and the maxillary alveolus [1].

\section{Computer Guided Implant Surgery}

Inherent diagnostic limitations, such as the expansion and distortion of the radiographic films in conventional radiology have been significantly improved by computed tomography (CT). CT is a technology that can be reformatted into a volumetric dataset in axial, coronal, and sagittal cuts. Such pre-operative radiographic images can then be up-loaded into a 3D implant planning software to generate multiple crosssectional and panoramic views $[29,30]$ and aide in preoperative implant planning. This technology enables the protection of critical anatomical structures and provides the esthetic and functional advantages of prosthodontic-driven implant positioning (Fig. 8). Once implant treatment planning is determined the data can be sent to manufacturing facilities for a guide splint and prosthesis construction. Some advantages of this technology include reduced operating time, postoperative recovery, and pain, as well as minimal surgical trauma [31].

\section{CONCLUSIONS}

Advances in reconstructive surgical techniques and innovative use of the dental implants have help the surgeons and prosthodontists to reconstruct more predictively and accurately patients with maxillofacial defects. Currently, tissue ingineered osteoinductive grafts as rhBMP-2 are capable to promote bone formation capable of supporting dental implants. Some other non-grafting techniques as "tilted osseointegrated implants" or Zygomaticus implants have showed high predictability in patient function and esthetic maxillofacial reconstruction.

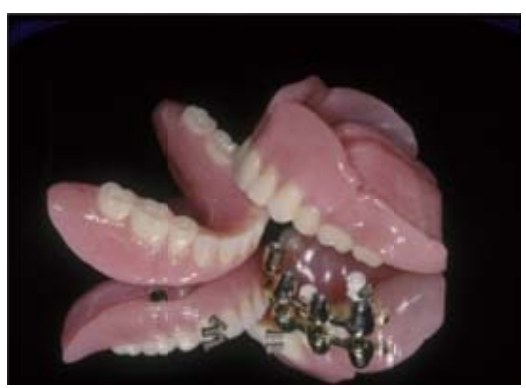

a

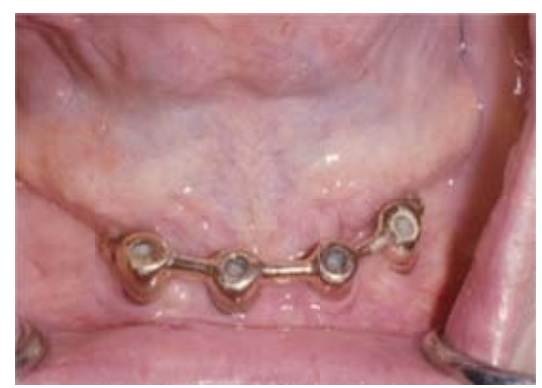

$\mathrm{b}$

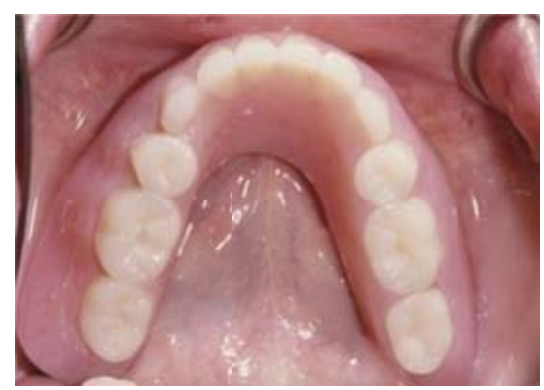

C

Fig. (5). Overdenture prosthesis. a; prosthetic components for bar and clip overdenture, b; metal bar in placed, c; mandibular overdenture in placed

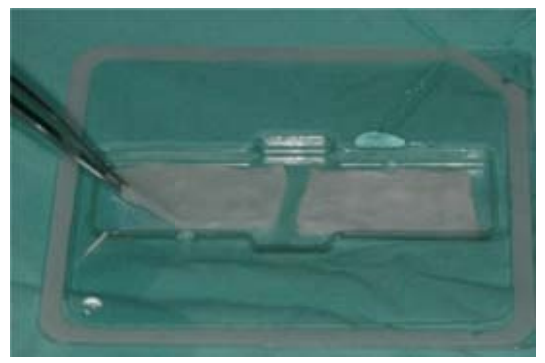

a
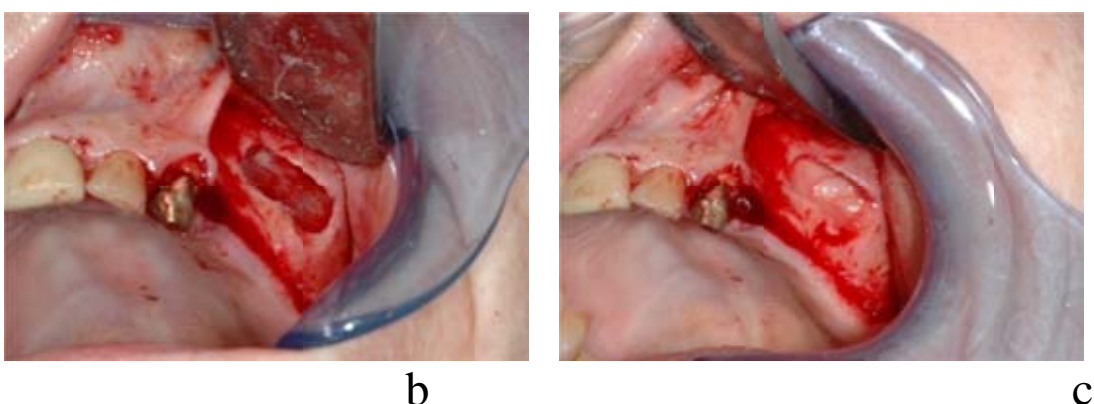

C

Fig. (6). Bone morphogenetic proteins. a; BMP2 on a collagen sponge carrier, b; left maxillary sinus window, c; BMP 2 graft placed 

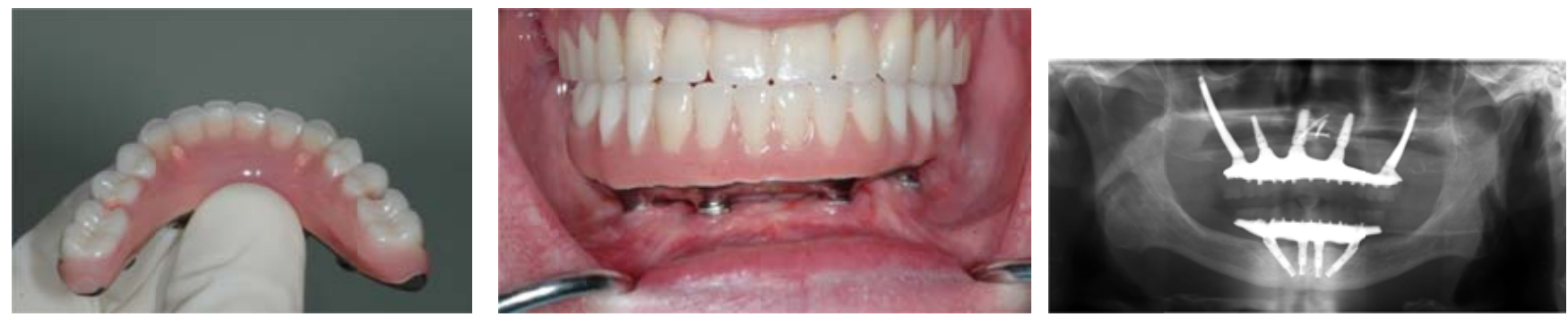

$\mathrm{a}$

$\mathrm{b}$

C

Fig. (7). Remote implant anchorage. a; Mandibular fixed detachable prosthesis, b; both fixed detachable prosthesis in placed, distal angulation of lower distal implants increases A-P spread avoiding cantilevers, bilateral zigomaticus implants avoids the need for extragrafting procedures.

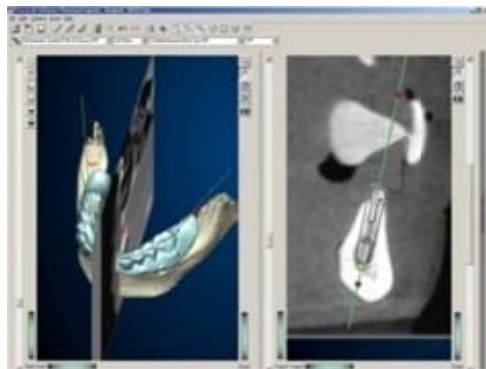

a

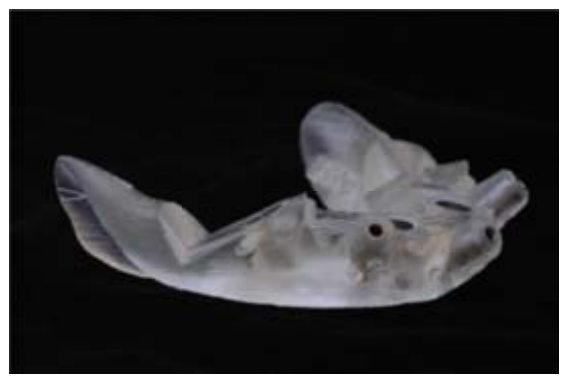

d

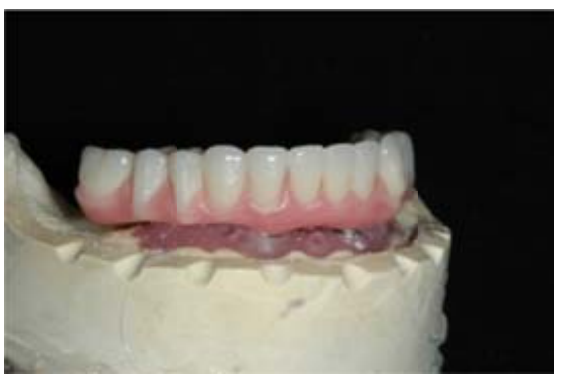

g

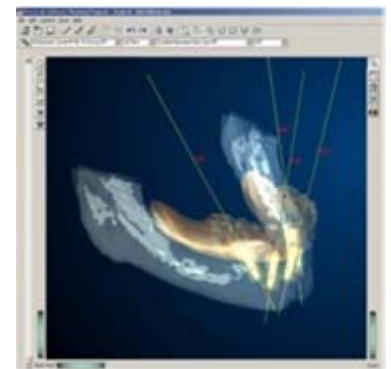

b
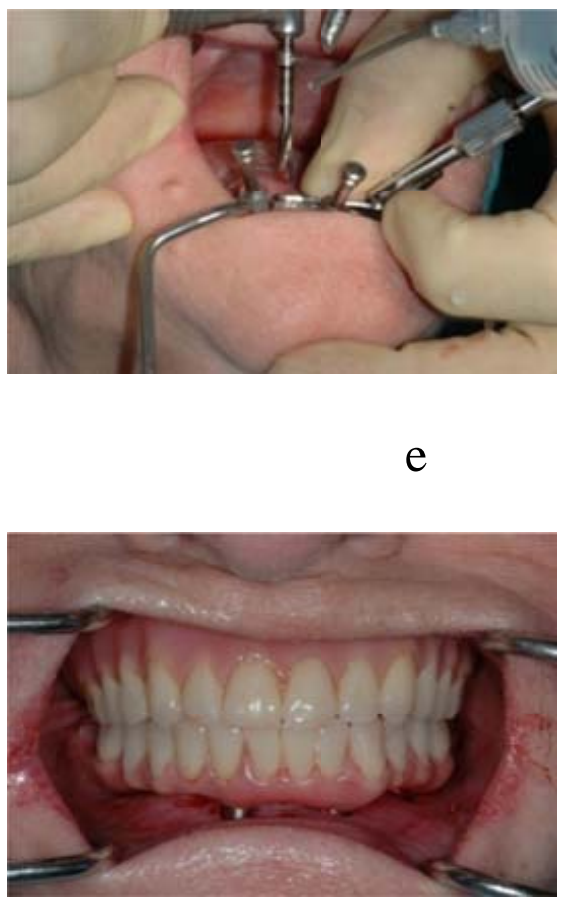

h e

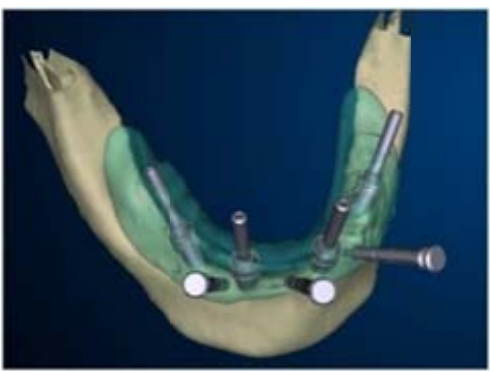

C

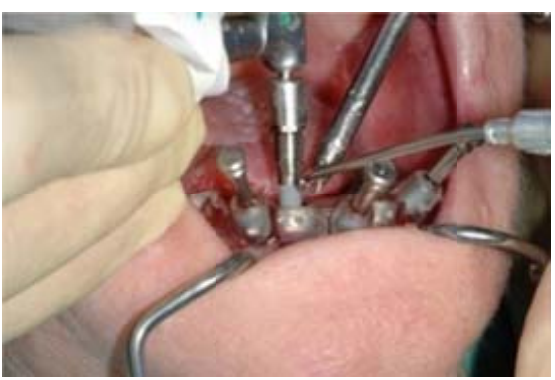

Fig. (8). Computer Guided Implant Surgery. a and b; Virtual planning for dental implants utilizing computer software and digital images of existing denture, $\mathbf{c}$; virtual surgical guide, $\mathbf{d}$; stereolithographic surgical guide, e; surgical guide in placed and drilling preparation for implant osteotomy sites, $\mathbf{f}$; implant placement aided with surgical guide, $\mathbf{g}$; temporary prosthesis already prepared in lab, $\mathbf{h}$; immediate insertion of temporary prosthesis after implant placement. 


\section{REFERENCES}

[1] Triplett RG, Schow SR, and Laskin DM. Oral and maxillofacial surgery advances in implant dentistry. Int $\mathrm{J}$ Oral Maxillofac Implants 2000; 15(1): 47-55.

[2] Ihara K. Multicenter experience with maxillary prostheses supported by Branemark implants: a clinical report. Int J Oral Maxillofac Implants 1998; 13(4): 531-8.

[3] McGregor IM. Cancer of the face and mouth. Livingston C, Ed. 1986.

[4] Curtis TA, Griffith MR, Firtell DN. Complete denture prosthodontics for the radiation patient. J Prosthet Dent 1976; 36(1): 66-76.

[5] Eckert SE . Endosseous implants in an irradiated tissue bed. J Prosthet Dent 1996; 76(1): 45-9.

[6] Wescott WB, Starcke EN, Shannon IL. Chemical protection against postirradiation dental caries. Oral Surg Oral Med Oral Pathol 1975; 40(6): 709-19.

[7] Reychler H. Treatment of buccal epidermoid carcinoma Up-to-date review. Ann Chir Plast Esthet 1991; 36(6): 486-97.

[8] Riediger, D. Restoration of masticatory function by microsurgically revascularized iliac crest bone grafts using enosseous implants. Plast Reconstr Surg 1988; 81(6): 861-77.

[9] Hidalgo, D.A. Fibula free flap: a new method of mandible reconstruction. Plast Reconstr Surg 1989; 84(1): 71-9.

[10] Urken, ML. Microvascular free flaps in head and neck reconstruction. Report of 200 cases and review of complications. Arch Otolaryngol Head Neck Surg 1994; 120(6): 633-40.

[11] Boyd JB. The iliac crest and the radial forearm flap in vascularized oromandibular reconstruction. Am J Surg 1990; 159(3): 301-8.

[12] Parel SM. Remote implant anchorage for the rehabilitation of maxillary defects. J Prosthet Dent 2001; 86(4): 377-81.

[13] Zarb GA. The edentulous milieu. J Prosthet Dent 1983; 49(6): 82531.

[14] Lundqvist S, Carlsson GE. Maxillary fixed prostheses on osseointegrated dental implants. J Prosthet Dent 1983; 50(2): 26270.

[15] Esser E, Wagner W. Dental implants following radical oral cancer surgery and adjuvant radiotherapy. Int J Oral Maxillofac Implants $1997 ; 12(4): 552-7$.

[16] Van Steenberghe. The rehabilitation of oral defects by osseointegrated implants. J Clin Periodontol 1991; 18(6): 488-93.

[17] Weischer T, Mohr C. Ten-year experience in oral implant rehabilitation of cancer patients: treatment concept and proposed criteria for success. Int J Oral Maxillofac Implants1999; 14(4): 521-8.

[18] Beumer J, Curtis TA, Marunick MT. Maxillofacial rehabilitation : prosthodontic and surgical considerations.St. Louis Ishiyaku EuroAmerica 1996; 546

[19] Schon, R. Peri-implant tissue reaction in bone irradiated the fifth day after implantation in rabbits: Histologic and histomorphometric measurements. Int J Oral Maxillofac Implants 1996; 11(2): 228-38.

[20] Granstrom G, Tjellstrom A, and Albrektsson T. Postimplantation irradiation for head and neck cancer treatment. Int $\mathbf{J}$ Oral Maxillofac Implants 1993; 8(5): 495-501.

[21] Granstrom G. Bone-anchored reconstruction of the irradiated head and neck cancer patient. Otolaryngol Head Neck Surg 1993; 108(4): 334-43.

[22] Hart GB, Mainous EG. The treatment of radiation necrosis with hyperbaric oxygen (OHP). Cancer 1976; 37(6): 2580-5.

[23] Zitzmann NU, Marinello CP. Treatment plan for restoring the edentulous maxilla with implant-supported restorations. removable overdenture versus fixed partial denture design. J Prosthet Dent 1999; 82(2): pp 188-96.

[24] Jemt T, Lekholm U. Implant treatment in edentulous maxillae. a 5year follow-up report on patients with different degrees of jaw resorption. Int J Oral Maxillofac Implants 1995; 10(3): 303-11.

[25] Herford AS, PJ Boyne. Reconstruction of mandibular continuity defects with bone morphogenetic protein-2 (rhBMP-2). J Oral Maxillofac Surg 2008; 66(4): 616-24.

[26] Boyne PJ. A feasibility study evaluating rhBMP-2/absorbable collagen sponge for maxillary sinus floor augmentation. Int $\mathrm{J}$ Periodontics Restor Dent 1997; 17(1): 11-25.

[27] Carter TG. Off-label use of recombinant human bone morphogenetic protein-2 (rhBMP-2) for reconstruction of mandibular bone defects in humans. J Oral Maxillofac Surg 2008; 66(7): 1417-25.

[28] Branemark PI. Surgery and fixture installation. Zygomaticus fixture clinical procedures. 1st ed. Goteborg, Sweden: Nobel Biocare AB 1998; p. 1.

[29] Schwarz MS. Computed tomography Part II. Preoperative assessment of the maxilla for endosseous implant surgery. Int Oral Maxillofac Implants 1987; 2(3): 143-8.

[30] Schwarz MS. Computed tomography Part I. Preoperative assessment of the mandible for endosseous implant surgery. Int J Oral Maxillofac Implants 1987; 2(3): 137-41.

[31] Parel SM, Triplett RG. Interactive imaging for implant planning, placement and prosthesis construction. J Oral Maxillofac Surg 2004; 62(Suppl 2): 41-7.

This is an open access article licensed under the terms of the Creative Commons Attribution Non-Commercial License (http: //creativecommons.org/licenses/by-nc/ $3.0 /$ ) which permits unrestricted, non-commercial use, distribution and reproduction in any medium, provided the work is properly cited. 